
Maffei

\title{
Representation of the soundscape quality in urban areas through colours
}

https://doi.org/10.1515/noise-2019-0002

Received Dec 08, 2018; accepted Apr 11, 2019

\begin{abstract}
Noise mapping is a useful and widespread method to visualise various items like the exposure to noise pollution, statistics of affected population, different noise source contribution analysis, and it is also a useful tool in designing noise-control plans. Some researches have moved a step further, proposing maps to represent the people perception of the acoustic environment. Most of these maps use colours as mere tools to display the spatial variability of acoustic parameters. In this paper the colours associated by interviewed people to different urban soundscapes have been analysed, and the possibility of using meaningful colours to represent the soundscape quality in noise mapping has been examined. For this purpose, correspondence analysis was applied on the data collected from on-site interviews, performed in the waterfront of Naples and its surroundings. The outcomes show that in the pedestrian areas nearby the sea, the blue colour was often associated with the soundscape rating, whereas in the areas nearby the sea but open to road traffic the interviewees selected mainly the blue and grey colours. In the areas away from the sea, a wider selection of colours was observed: red and grey were predominantly selected in the areas open to road traffic and green, yellow and red in the green areas.
\end{abstract}

Keywords: Perception, soundscape, acoustic environment, colours

\footnotetext{
*Corresponding Author: Virginia Puyana-Romero: Faculty of Sound and Acoustic Engineering, University of Las Americas, 170125, Quito, Ecuador; Email: virginia.puyana@udla.edu.ec

Christiam Garzón: Faculty of Sound and Acoustic Engineering, University of Las Americas, 170125, Quito, Ecuador

Giuseppe Ciaburro, Luigi Maffei: Dipartimento di Architettura e Disegno Industriale, Università degli Studi della Campania “Luigi Vanvitelli”, 81031, Aversa, Italy

Giovanni Brambilla: Formerly Istituto di Acustica e Sensoristica “Orso Mario Corbino”, Consiglio Nazionale delle Ricerche, 00133, Roma, Italy
}

\section{Introduction}

The complex task of studying the acoustic environment involves the use of tools helping to interpret its state and evolution. Indicators are commonly considered in urban planning and environmental impact assessment to evaluate the need to take action for the improvement of the acoustic environment. Most of these indicators measure objective properties of the acoustic environment, such as noise levels, number of events, or psychoacoustic parameters. Some others deal with subjective ratings of specific features, such as the soundscape quality, noise annoyance or acoustic comfort. Quantitative and qualitative parameters can be applied together to provide a complete a description as possible of the acoustic environment. While quantitative parameters are expressed in numerical scales, qualitative parameters may be expressed in numerical (as the ones rated from 0 to 100) or ordinal scales (as the Likert scale). In the evaluation of the acoustic environment in urban areas, it is advisable to represent the spatial and even the temporal changes of acoustic and non-acoustic factors. For instance, coloured maps are often used to represent the spatial variability of the variables of interest. Community based monitoring initiatives also display these kind of maps to represent the collected information on the acoustic environment $[24,41,42,58]$. However, in these maps colours are used as mere replacements of numeric values, without any direct kind of meaning associated with their use.

Colours have been used for noise maps as a mean to represent different noise levels, but their potential to be associated with a specific soundscape (or with a landscape or smellscape) has not been investigated yet. Thus, it seems to be worth to investigate the colours that a specific acoustic environment may evoke on individuals in order to make more representative soundscape maps.

The aim of this study is to analyse the relation between soundscape, defined by the ISO 12913-1:2014 as the "acoustic environment as perceived or experienced and/or understood by a person or people, in context" [50], and some acoustic parameters, as well as colours associated to the

๑ Open Access. (c 2019 V. Puyana-Romero et al., published by De Gruyter. 
soundscape, in in order to evaluate the potential of using colours as additional soundscape indicators in urban open spaces for soundscape mapping.

\subsection{Colours, sounds, and emotional reactions}

Different studies have established connections between what a person sees, listens and feels simultaneously through the audio-visual interaction. Some of them have focused on different aspects of sound, suggesting that colours may play a significant role in its appraisal $[1,15$, $27,62]$. These studies have evaluated the perception of a specific sound or acoustic environment in relation with the colour of the object or the atmosphere in which they can be heard. Laboratory tests were conducted in most of them $[16,52,57]$, using acoustic recordings and visual materials (photos or videos) or Immersive Virtual Reality scenarios [37, 38].

Patsouras et al. [52] found that the sound of a train simultaneously reproduced while displaying images of red trains caused a perception of loudness higher than displaying green trains. Rader et al. [57] compared the results of the previous study with the ones carried out on subjects of a different nationality with similar but more remarkable results, concluding that the colour-sound interaction might be more noticeable by subjects from one country than from another. Evaluating different means of transport, Menzel et al. [48] also evidenced differences in the loudness perception of a car pass-by depending on its colour. Ma and Nie [36] explored the variation of noise annoyance resulting from different levels of road traffic noise heard in indoor environments. The authors showed that by improving the combination of colour and lighting conditions, the annoyance produced by the road traffic noise in indoor environment can be reduced. The effects of the visual characteristics of the acoustic barriers on the perception of railway noise were analysed by Maffei et al. [39] through Immersive Virtual Reality scenarios, concluding that green colour barriers seem less loud than others. The audio-visual influence on the acoustic comfort assessment was analysed in the interior of a metro wagon [13], through different colour decoration. The study showed that the beige metro was judged more relaxing than the blue one and more harmonious than the blue and yellow. Maffei et al. [37] evaluated the effects of colours on the auditory perception of a wind farm in a quiet area, concluding that green and white turbines are preferred to brown and red ones in terms of integrations with the environment, visual and sound pleasantness, and annoyance. Further informa- tion about the color-sound interaction can be found in a review article written by this research team [56].

The analysis of different researches leads to the conclusion that colours, e.g. [26, 31, 59, 65], and sounds, e.g. $[2,3,10]$, independently considered may raise similar emotional responses. Both colours and sounds may be associated with emotions such as sadness, annoyance or calmness.

Dealing with the association between sounds, colours and emotions, many studies maintain that similar psychological reactions caused by music and colours are based on the correspondence between their physical properties. For example, there are different theories trying to explain the relationship between music and colour through the association among their amplitude and wavelength [54, 61], or between hue and saturation of colours with pitch and timbre of music $[11,18]$. This association is manifested remarkably in individuals with auditory-visual synaesthesia, in which acoustic stimuli may evoke visual sensations, e.g. $[21,43,49]$. Nevertheless, there are many studies suggesting that ordinary people are also able to experience cognitive associations based on emotional matching between music and colours, e.g. [28, 35, 51, 63, 64]. In that regard, some authors believe that the sound-colour synaesthesia employs similar mechanisms used by not synesthetic individuals in cross modal perception [66]. In Strle et al. [63] the authors maintain that the correlations between colours, music and emotions are influenced by the context, concluding that music and colours can be used to induce affective responses in individuals. The outcomes obtained in [51] support the "emotional mediation hypothesis" asserting that participants chose colours that evoke similar emotional responses to the ones aroused by the classicist style music that they were listening. In [4] the authors claim that songs defined as happy are mainly associated with bright colours such as red, yellow, green and blue, while songs defined as sad are mainly associated with grey colour.

Most of the researches above cited are related with the association between colour, music or pure tones and emotions. Notwithstanding, just a few examples may be found in literature dealing with the association between colour, sound environment and emotions. For instance, in [34], excerpts of acoustic environment recordings (without photos or video depiction) are associated in a laboratory experiment to the two-dimensional model of perceived affective quality of the acoustic environment [3], and a set of predetermined colour patches. Results showed that there are patterns in the way that participants associate colours and recordings of the acoustic environment. 


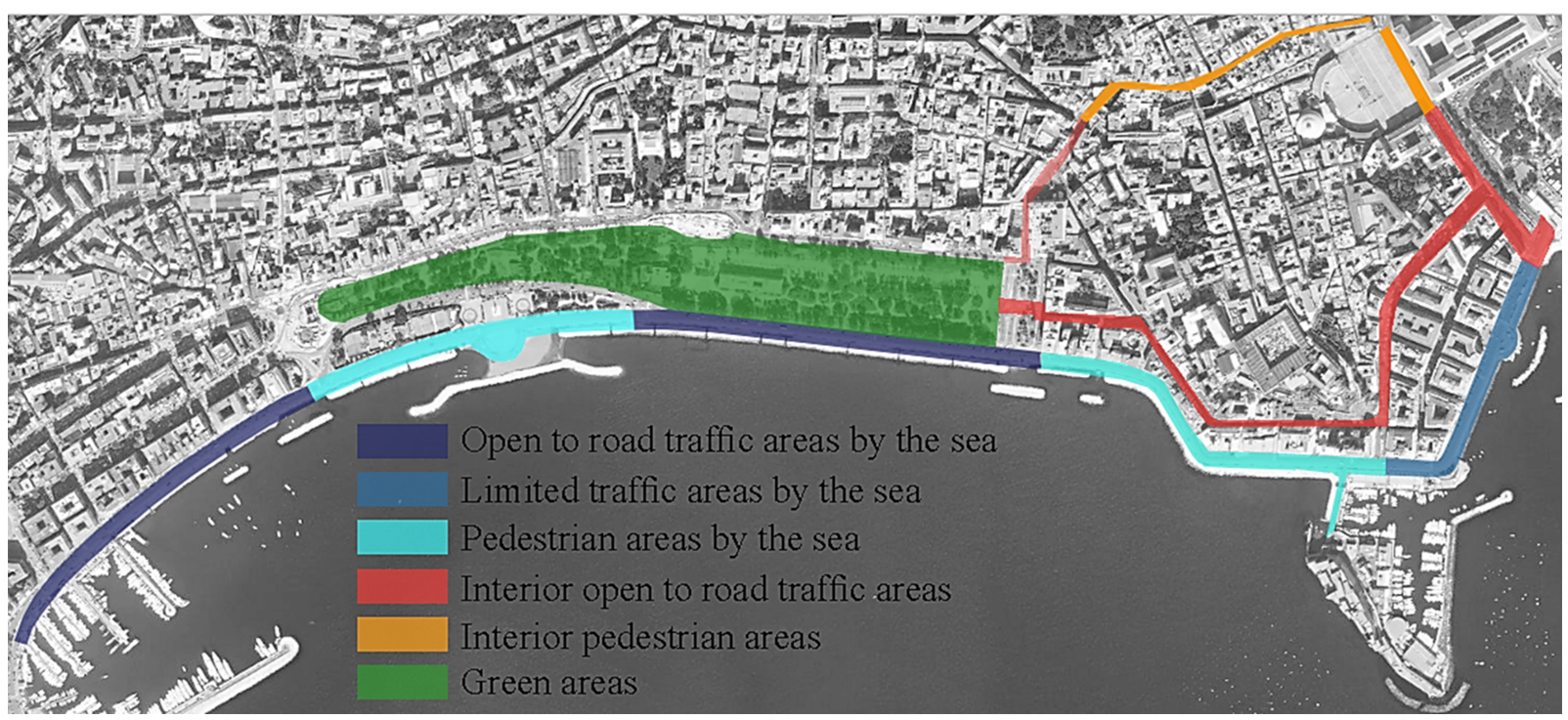

Figure 1: The selected study areas in Naples.

Some researches go one step further, trying to find out if the correspondence between colour and sound may facilitate the information processing while conducting cognitive tasks [45, 47]. In [12], target discrimination task was used to evaluate if the associations between sound attributes and colour properties could improve participants' efficiency in cognitive tasks. The results showed that participants answered faster and more accurately to the question when colour and sounds (simultaneously displayed and reproduced while questions were formulated) were congruent. Marks et al. showed that when the pitch is congruent with the brightness of colours, participants responds with more efficiency than when the cited features of sound and colour were not congruent [44].

The present research is aimed to evaluate the assumption that there are cross-modal correspondences between audio and visual modalities [4, 32, 35, 63], in particular, between outdoor soundscapes and colours. In order to evaluate the use of colours as additional tools for graphical representation of soundscape in maps, comparison between objective and subjective descriptors of soundscape and the colour associated to it by the interviewees were performed.

\section{Materials and methods}

The study area included a stretch of the waterfront of Naples, with lively bars, historical buildings and a bustling promenade with the neighbouring sites. The western boundary of the study area was the intersection of
"Mergellina" and "Francesco Caracciolo" streets; the eastern boundary was formed by the "Ammiraglio Ferdinando Acton" and "Francesco Caracciolo" streets. The locations where the noise survey was performed were selected in order to cover a range of urban spaces with different features (Figure 1): green areas, places nearby the sea and areas with different kinds of traffic flows. Villa Comunale, one of the biggest urban parks of the city, and the waterfront of Naples are within the extent of the study area. The areas were selected regarding their soundscape and landscape features, to evoke a diversity of positive and negative sensations in the participants of the study.

\subsection{Materials}

The present study deals with data on objective acoustic parameters and subjective perceptual data collected during two field surveys, carried out in the study area in winter 2014 and summer 2016. Face-to-face interviews were carried out on weekdays and weekends from 10:00 to 17:00 hours. Participants, selected randomly, were asked to fill in a questionnaire dealing with the assessment of the soundscape and other features of the area in which they were interviewed.

Binaural recordings in fixed locations were taken simultaneously with the interviews by means of binaural headphones Sennheiser HDC 451, connected to a portable digital audio recorder (M-Audio Microtrack 24/96). An acoustic calibrator 01 Metravib "CAL21" was used to calibrate the equipment. 

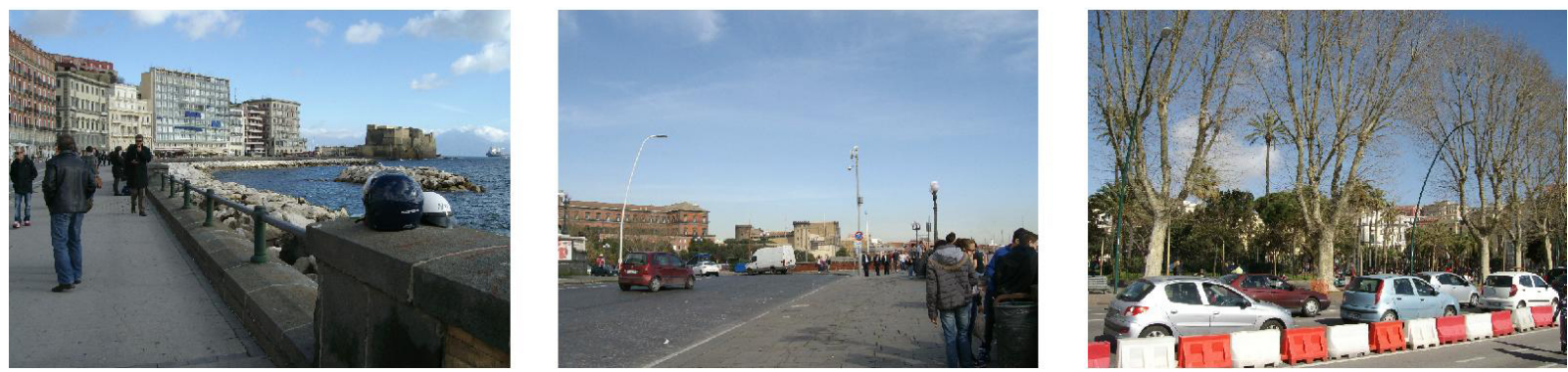

Figure 2: Areas by the sea; from left to right: pedestrian areas (code Sea_PE), limited traffic areas (Sea_LI) and open to road traffic areas (Sea_TR).
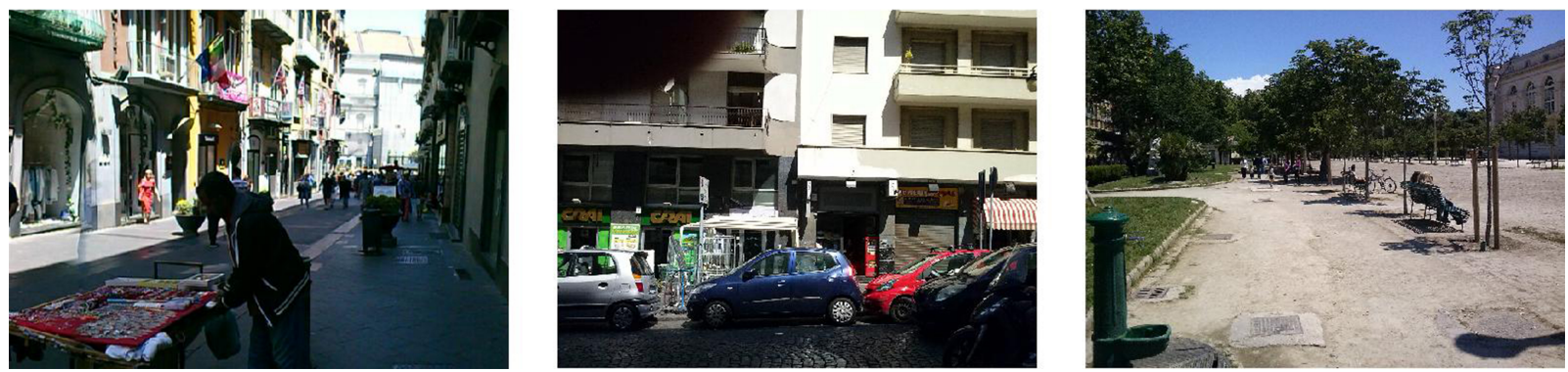

Figure 3: Interior areas; from left to right: pedestrian areas (code Int_PE), open to road traffic areas (Int_TR) and green areas (Int_Park).

The survey campaign was carried out in 24 locations, classified "a priori" into six types of area depending on distance from the sea (Figure 1), the type of road traffic and the presence of vegetation. In particular, the areas close to the sea were classified in (Figure 2): "Pedestrian areas nearby the sea" (code Sea_PE), "Limited traffic areas nearby the sea" (Sea_LI) and "Open to road traffic areas nearby the sea" (Sea_TR). The areas away from the sea were divided into (Figure 3): "Interior pedestrian areas" (code Int_PE), "Interior open to road traffic areas" (Int_TR) and the areas with the presence of vegetation "Green areas" (Int_Park).

Among other questions, interviewees were asked to select the colour they would associate to the soundscape that they experienced during the interview. The questionnaire was printed in black and white to avoid influence on the responses of participants. For the same reason, no visual scale or list of colours were proposed for answering to the question on colour association, so that the response would correspond as much as possible to an evoked colour, and not to a random selection from a list.

Table 1 reports the main questions submitted to the participants. Interviewees were asked to select the sound sources heard during the interviews, grouped into 10 categories, namely road traffic, aircraft fly-overs, construction works, voices and steps, music, bells, animals, leaves, wind and water. They were also asked to select the predominant sound source heard, among the previous ten cate- gories. Other questions dealt with the soundscape quality and some of its attributes in the locations under study.

A sample of 227 subjects was interviewed in the selected locations. The answers of three of them, which had chosen pink, purple and black as colour associated to the soundscape, were not included in the data analysis being considered as outliers, according to the attribute value frequency procedure (AVF) for categorical data [29]. Thus, nine colours have been considered, as reported in Figure 4.

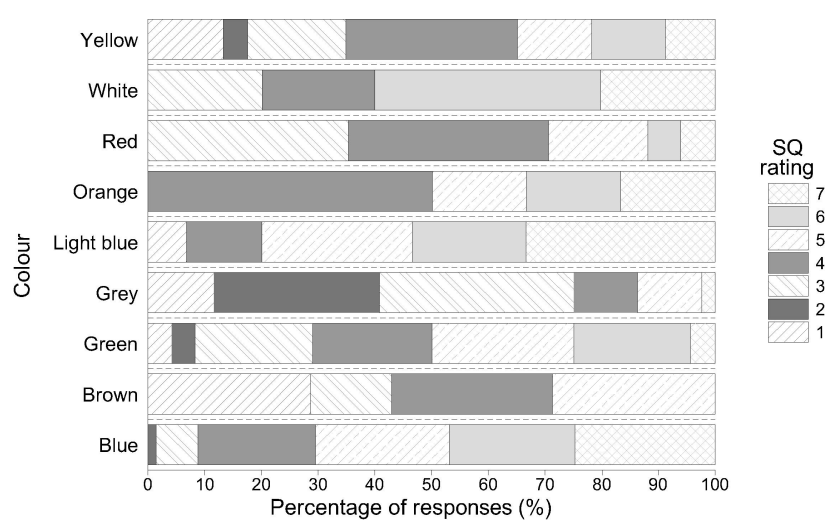

Figure 4: Stacked bar plot of the colours associated with each score given to the soundscape (SQ). 
Table 1: Questions included in the poll used for the present study.

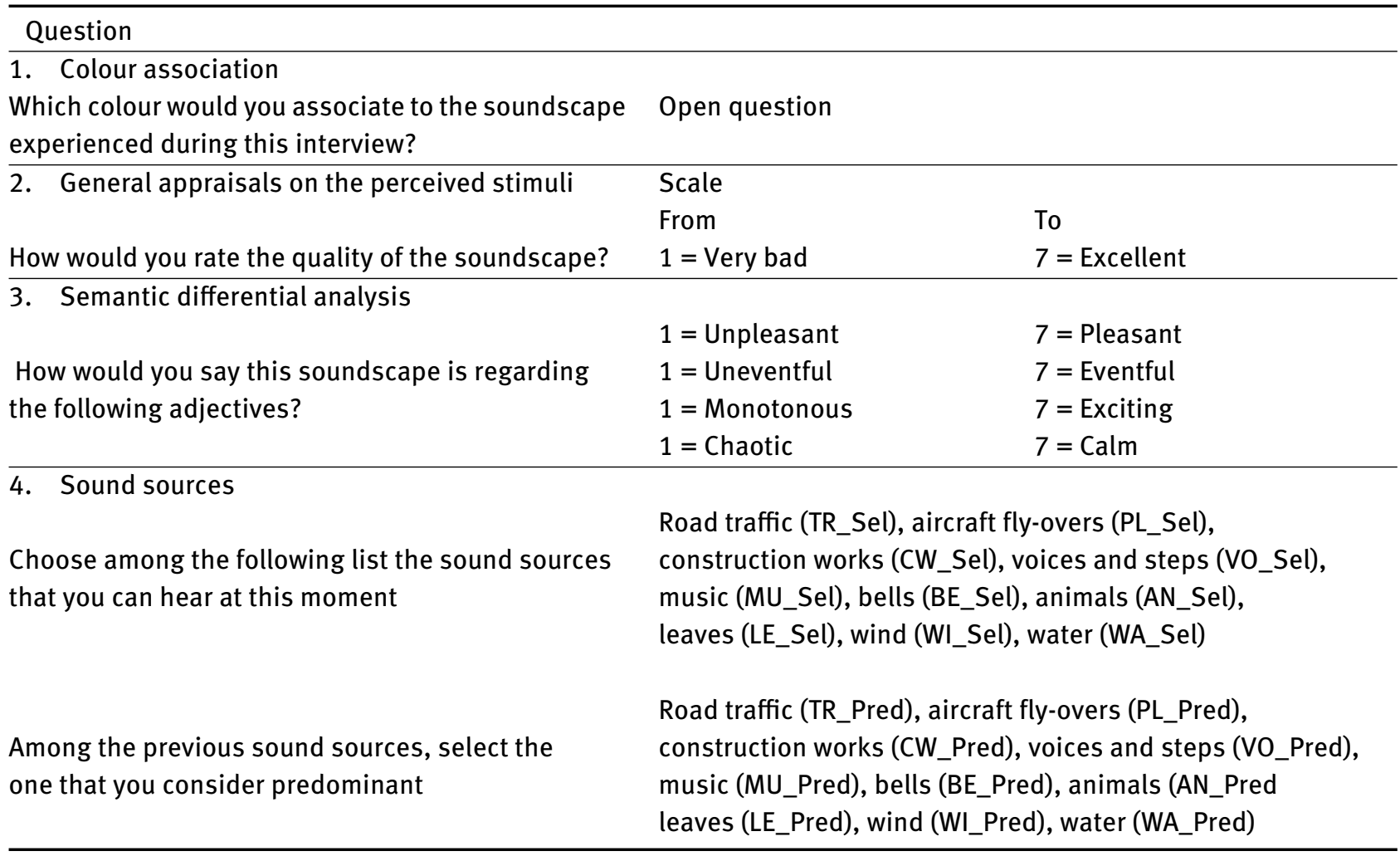

\subsection{Methods}

The sound recordings were post-processed to determine some acoustical parameters, namely $\mathrm{L}_{e q}, \mathrm{~L}_{A e q}$, and the percentiles $\mathrm{L}_{A 5}, \mathrm{~L}_{A 10}, \mathrm{~L}_{A 50}, \mathrm{~L}_{A 90}, \mathrm{~L}_{A 95}$, as well as the average value of psychoacoustic descriptors sharpness (S), roughness (R), fluctuation strength $(\mathrm{F})$ and the $5^{\text {th }}$ percentile of loudness $\left(\mathrm{N}_{5}\right)$ that is a good predictor of the subjectively perceived overall loudness for temporal varying sounds [17].

The association among the variables was evaluated through different statistical methods in relation of the type of variables under consideration. Spearman's correlation coefficient has been determined for the eleven acoustical parameters, while the Chi-Squared Independence Test was used to test the association between pairs of categorical variables. To measure the strength of association between categorical variables, the Cramer's V test was applied considering the following scale: $0-0.30=$ no relationship, $0.31-0.50$ weak relationship, $0.51-0.70=$ moderate relationship, $0.71-1$ = strong relationship.

In addition, the soundscape perceived quality was taken as dependent variable in two linear regression models considering as independent variables the eleven acoustical parameters in the first model (called AP, Acoustic Pa- rameters) and the nine colours associated to the soundscape, codified in dummy variables, in the second model (called C, Colours). Backward stepwise regression has been applied to reduce the number of independent variables. The data set was split into training (dataset portion $=0.7$ ) and test subsets and $\mathrm{k}$-fold cross validation, with $\mathrm{k}=10$, was applied with 5 repetitions using the package "caret" (Kuhn, 2008) running under the R software (R Core Team, 2013). The performances of the two models were compared to evaluate the potential of the colours to improve the soundscape quality prediction.

Afterwards, correspondence analysis was used to interpret the relationship between soundscape quality colours and locations - colours. Correspondence analysis is an exploratory technique that may be applied to categorical and nominal data. It displays and summarizes the relationships of large contingency tables of frequency through a two dimensional graphical form [19, 20]. In addition, multiple correspondence analysis was performed to evaluate globally the results in all the types of areas. Correspondence analyses and multiple correspondence analysis were performed by means of the package "FactoMineR" [30] running under the R software. 
Table 2: Association between colours and soundscape quality (SQ) with the heard ( Sel) and predominant (Pred) sound sources. Only the pair of variables with $p$-value in the Chi-square test lower than 0.05 are reported (See Table 1 for abbreviations).

\begin{tabular}{|c|c|c|c|c|c|c|}
\hline \multirow[b]{2}{*}{ Noise sources } & \multicolumn{3}{|c|}{ Colours } & & \multicolumn{2}{|c|}{ SQ } \\
\hline & & Value & $\mathrm{p}$-value & & Value & $p$-value \\
\hline \multirow{2}{*}{ TR_Sel } & Pearson $\chi^{2}$ & 34.263 & $<0.001$ & Pearson $\chi^{2}$ & 18.192 & 0.006 \\
\hline & Cramer & 0.393 & & Cramer & 0.286 & \\
\hline \multirow{2}{*}{ TR_Pred } & Pearson $\chi^{2}$ & 46.361 & $<0.001$ & Pearson $\chi^{2}$ & 53.514 & $<0.001$ \\
\hline & Cramer & 0.457 & & Cramer & 0.491 & \\
\hline \multirow{2}{*}{ VO_Sel } & Pearson $\chi^{2}$ & 23.081 & 0.003 & Pearson $\chi^{2}$ & 15.647 & 0.016 \\
\hline & Cramer & 0.322 & & Cramer & 0.265 & \\
\hline \multirow{2}{*}{ WI_Sel } & Pearson $\chi^{2}$ & 15.893 & 0.044 & Pearson $\chi^{2}$ & 24.860 & $<0.001$ \\
\hline & Cramer & 0.268 & & Cramer & 0.335 & \\
\hline \multirow{2}{*}{ WA_Sel } & Pearson $\chi^{2}$ & 44.835 & $<0.001$ & Pearson $\chi^{2}$ & 34.142 & $<0.001$ \\
\hline & Cramer & 0.449 & & Cramer & 0.392 & \\
\hline \multirow{2}{*}{ WA_Pred } & Pearson $\chi^{2}$ & 35.699 & $<0.001$ & Pearson $\chi^{2}$ & 28.568 & $<0.001$ \\
\hline & Cramer & 0.401 & & Cramer & 0.359 & \\
\hline \multirow{2}{*}{ Location } & Pearson $\chi^{2}$ & 136.480 & $<0.001$ & Pearson $\chi$ & 83.471 & $<0.001$ \\
\hline & Cramer & 0.351 & & Cramer & 0.274 & \\
\hline
\end{tabular}

\section{Results}

\subsection{Association between variables}

The results of the Chi-Squared Independence Test revealed an association between the colours and soundscape quality $\left(\chi^{2}\right.$ Pearson $=120.97$, $\mathrm{p}$-value $\left.<0.01\right)$. To determine the strength of this association, Cramer's V test was performed, giving a value of 0.301 , that is a poor relationship between the two variables, according to the scale described in 2.2. Figure 4 shows the stacked bar plot of colours associated with each score given to the soundscape. The percentage value of responses is computed referring to all the occurrencies of the same colour.

The same tests were performed to evaluate the association between heard sound sources, predominant sound sources and locations with both colours and the soundscape quality. The summarized results are shown in Table 2, where only the pair of variables showing association between them, even if poor, are reported.

Traffic and water sources show high relationship with both colours and soundscape quality in the studied context. When the predominant sound source is either water or traffic, both colours and soundscape quality have association with similar values.

The relationship of colours and the soundscape quality with the location was also analysed. An association between colour and location was observed, but no association was found between soundscape quality and location. This lack of association may be due to the interpretation

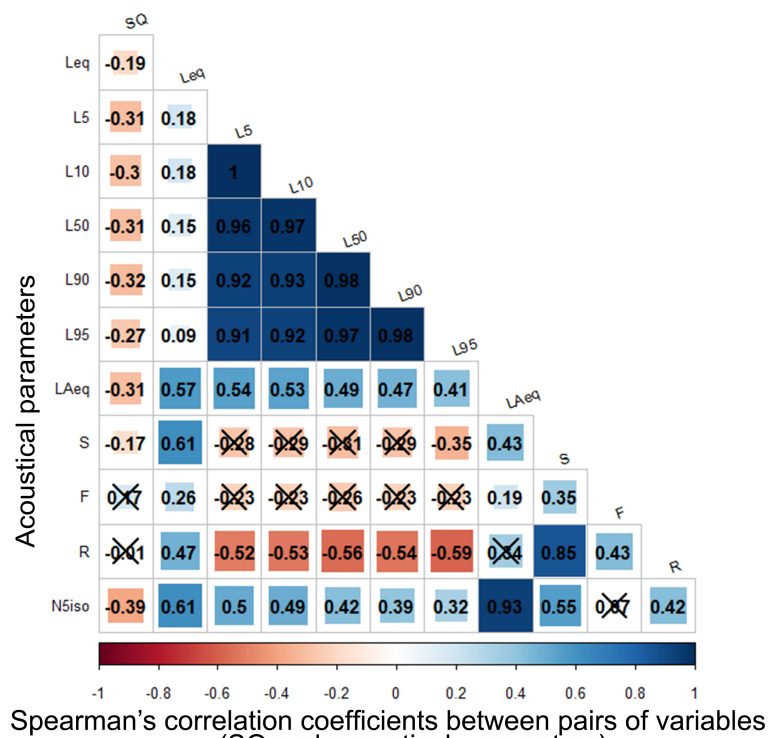

(SQ and acoustical parameters)

Figure 5: Spearman's correlogram between soundscape quality (SQ) and acoustical parameters. Cells with " $X$ " report correlation coefficients not significant at $95 \%$ confidence level.

made by interviewees of the term soundscape, as no definition was given to participants during the interviews.

In addition, the degree of association of the soundscape quality and the objective acoustic parameters was calculated. As the latter were continuous variables, Spearman's correlation was calculated. The association of the acoustical parameters considered and the soundscape quality was also weak, as shown by the first column of the correlogram reported in Figure 5. However, the loudness 
Table 3: Performance of the two linear regression models.

\begin{tabular}{ccccc}
\hline Model & Root Mean Squared Error & R squared & \multicolumn{2}{c}{ Testing model } \\
& & & Accuracy & Kappa \\
\hline Acoustical Parameters (AP) & 1.54 & 0.259 & 0.234 & 0.045 \\
Colours (C) & 1.47 & 0.333 & 0.281 & 0.104 \\
\hline
\end{tabular}

$\mathrm{N}_{5}$ was the parameter best correlated with $\mathrm{SQ}$ and, as expected, negatively, that is the SQ increases with decreasing of $\mathrm{N}_{5}$. The percentile levels in $\mathrm{dB}(\mathrm{A}) \mathrm{L}_{n}$ were highly correlated one another.

\subsection{Multivariate linear regression}

In the linear regression model of soundscape quality (SQ) predicted by the acoustical parameters (AP model) the backward stepwise regression left out two variables, that is fluctuation stregth $\mathrm{F}$ and sharpness $\mathrm{S}$, while in the model dealing with colours ( $\mathrm{C}$ model) three were left out, namely green, red and yellow. The comparison between the two models obtained by the $10 \mathrm{k}$-fold cross validation showed that the performance of the $\mathrm{C}$ model was better than that of the AP, as shown in Table 3. In the latter the most important variable was the $5^{\text {th }}$ percentile of loudness $\left(\mathrm{N}_{5}\right)$, followed by $\mathrm{L}_{A 95}$ and $\mathrm{L}_{A e q}$, while in the former the most important variable was grey, followed by blue and white.

It is worth to point out that the value of $R$ squared in both models is not high and this is due, most likely, because of other non-acoustic factors, influencing the rating of the soundscape quality, are not included in the model, among them cleanliness, maintenance, environmental quality and subjective expectation [40].

\subsection{Correspondence analysis}

Two correspondence analyses were performed to evaluate the relationship of each specific colour with the soundscape quality (SQ) and the locations (type of area). The interpretation of the correspondence analysis results is aimed to evaluate whether a significant dependence exists between the variables or not [19]. Two methods were used to detect the dependence, namely the square root of trace [19] and the Chi-Square statistics [46].

\subsubsection{Correspondence analysis between type of area and colours}

The square root of the trace (correlation coefficient) between type of area and colours was 0.78, indicating a strong relationship between the colours associated to the soundscape and the type of area. Chi-Square statistics was also calculated, as it is a more rigorous method for examining the association between variables [25]. The statistics $\chi^{2}$ (136.48) and the $\mathrm{p}$-value $\left(1.836 \mathrm{e}^{-12}\right)$ supported the results of the square root of the trace test.

The number of dimensions to be considered in the correspondence analysis was determined by the scree plot reported in Figure 6, where the horizontal red dashed line is the threshold above which dimensions should be considered significant and included in the data interpretation $[5,6]$. The results of the correspondence analysis of the contingency table of colours and types of area are plotted in Figure 7.

Dimension 1 explains $46.0 \%$ of variance, while dimension 2 explains 34.8\%. Hitherto, it seems that correspondence analysis was successful in representing the contingency table in the two dimensional space. An overall retention of $80.8 \%$ was achieved for the two dimensions.

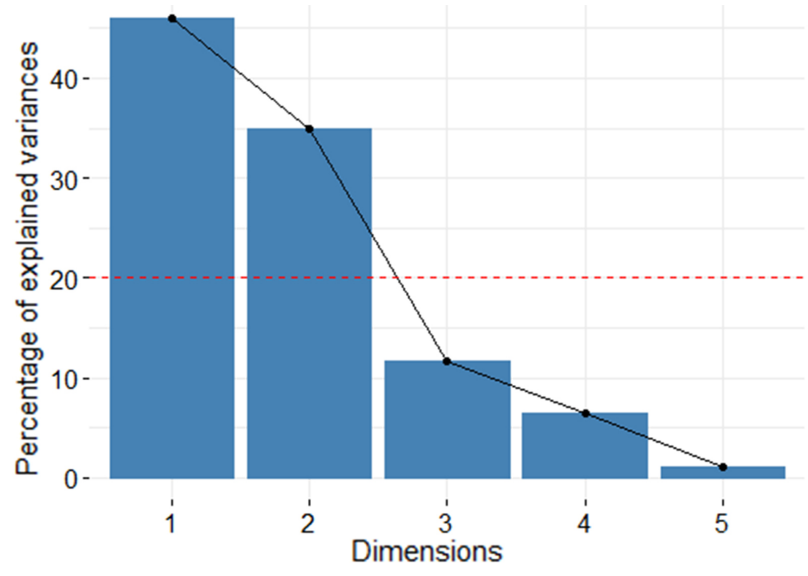

Figure 6: Percentage of the explained variance by each dimension. The red dashed line represents the $n$ average eigenvalue above which the axis should be taken into account in the interpretation of the results. 


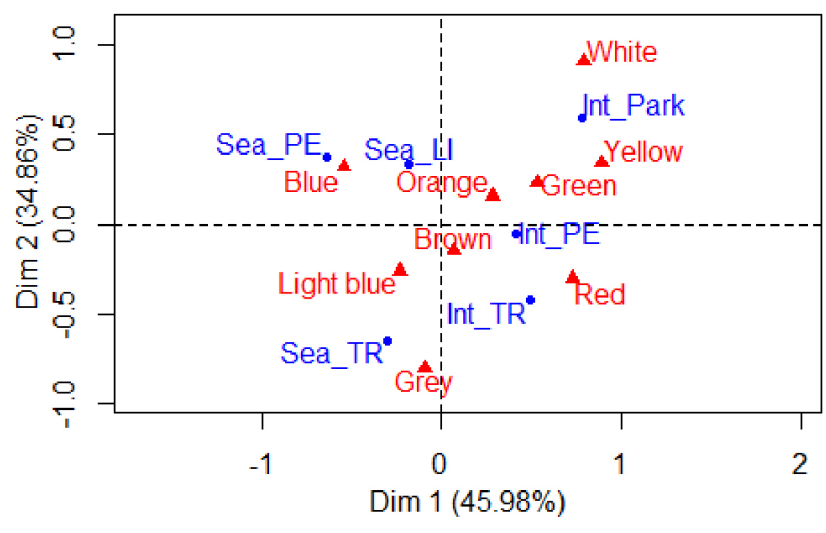

Figure 7: Correspondence analysis between colours and types of area. Blue dots represent the type of area and red triangles the colour associated to the soundscape.

The interpretation of the dimensions was done regarding the contribution of each colour to the total inertia accounted for by the $\mathrm{X}$ and $\mathrm{Y}$ axes considered independently [6]. Because there were nine different colours, the contribution of the categories higher than $100 / 9=11.1 \%$ over the axis was considered. The colours mostly contributing to dimension 1 are blue (38.3\%), followed by yellow (27.8\%), whereas the one highest contributor to dimension 2 is grey $(59.1 \%)$, followed by blue (17.8\%), as shown in Table 4.

Table 4: Dimension contribution (\%) and quality of the columns representation $\left(\cos ^{2}\right)$.

\begin{tabular}{ccccc}
\hline Colours & $\begin{array}{c}\text { Dim1 } \\
\text { Type of } \\
\text { area }\end{array}$ & $\cos ^{2}$ & $\begin{array}{c}\text { Dim2 } \\
\text { Type of } \\
\text { traffic }\end{array}$ & $\cos ^{2}$ \\
\hline Blue & $\mathbf{3 8 . 3}$ & 0.74 & $\mathbf{1 7 . 8}$ & 0.26 \\
Brown & 0.1 & 0.04 & 0.3 & 0.16 \\
Green & $\mathbf{1 1 . 9}$ & 0.51 & 2.7 & 0.1 \\
Grey & 0.6 & 0.01 & $\mathbf{5 9 . 1}$ & 0.92 \\
Light blue & 1.3 & 0.27 & 2.1 & 0.35 \\
Orange & 0.8 & 0.17 & 0.3 & 0.05 \\
Red & $\mathbf{1 4 . 3}$ & 0.48 & 3.2 & 0.08 \\
White & 5.0 & 0.32 & 8.6 & 0.42 \\
Yellow & $\mathbf{2 7 . 8}$ & 0.74 & 5.7 & 0.11 \\
\hline
\end{tabular}

However, not all of the colours or types of area are equally represented. Determining the quality of representation of a particular row or column provides additional information on the interpretation of the relationships in the contingency table. The quality of the representation can be evaluated through the sum of the squared cosine of that row or column over the specific dimensions [6]. If a row item is well represented by two dimensions, the sum of the squared correlations is high and tends to be 1 . According to this criterion for the limited traffic areas nearby the sea and the pedestrian areas away from the sea a higher dimensional solution is probably necessary to understand them.

Figure 8 shows a simplification of the correspondence analysis results, according to the information reported in the previous paragraphs. The colours that did not have a percentage of contribution higher than $11.1 \%$ have not been considered for the interpretation of the available data, as is also the case with the type of areas (see Table 4). The Int_PE was discarded from the interpretation because of its low contribution to both dimensions $(7.7 \%$ and $0.2 \%$ to dimension 1 and 2 respectively), and the Sea_LI was not considered because of its poor quality of representation.

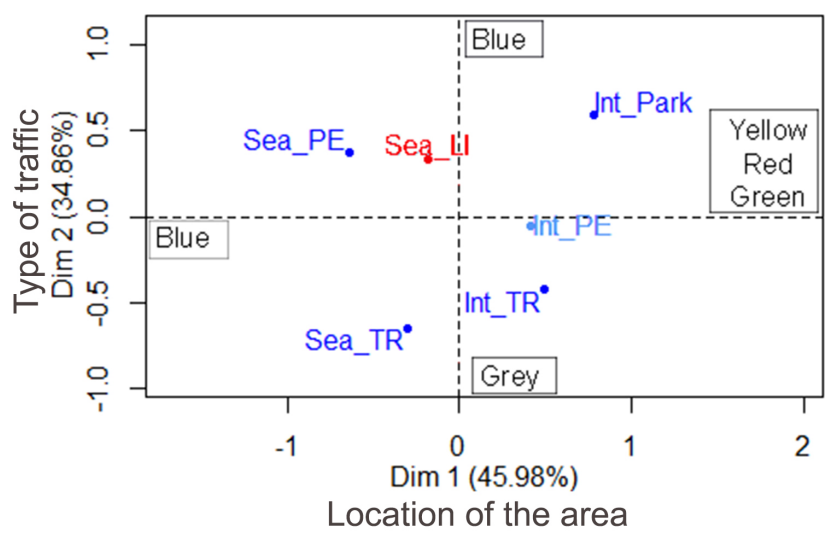

Figure 8: Representation of the correspondence analysis. The colours are reported within rectangles and the types of area are represented with dots (blue: contribution higher than $14.3 \%$ (100/7), light blue: contribution lower than $14.3 \%$ and red: poor representation in the dimensions).

Dealing with the interpretation of the vertical axis, it may be associated to the type of traffic. The pedestrian areas are represented on the positive part of this axis, whereas the areas with traffic are located in the negative part. In [4], the blue colour is associated to positive emotions, such as calmness, quietness or restfulness, and grey colour is associated to negative emotions, such as depressions, confusion or sadness [23,26]. Thus, the acoustic environment of the pedestrian areas nearby the sea and areas within the park is mainly associated to blue colours, and hence it may be associated with positive emotions, while areas open to traffic (nearby the sea and the interior ones) are associated to grey colour, and hence to negative emotions. The acoustic environment of the pedestrian areas nearby the sea is strongly associated with blue colour in 
both dimensions, while the one of the areas nearby the sea and open to traffic is associated to grey colour, and weakly correlated with blue.

The horizontal axis may be associated to the location of the areas. The areas nearby the sea are represented in the left side of this axis, whereas the areas away from the sea are represented in the right one. The acoustic environment of the areas nearby the sea is mainly related to the blue colour, while the one of the areas away from the sea is more related to green, yellow or red, independently from the type of traffic. The acoustic environment of the park is strongly associated to yellow, red and green, and weakly associated to blue. The green colour was reported in other studies to have restorative effects [7], to generate sensations of safety [53], or to create atmospheres that promote the creativity in individuals [33]. Thus, those characteristics may be related to the acoustic environment of the park. White and yellow were the most chosen colours in a children's play area within the park. White colour was considered a positive colour, link to innocence, peace and hope, and yellow was generally seen as a lively and energetic colour, arising emotions such as happiness and excitement [26]. Thus, these kind of emotions may be linked to the acoustic environment of the children's play areas.

Figure 9 shows the percentage of people who had chosen a specific colour in each area. The comparison of the areas nearby the sea (Sea_PE, Sea_LI and Sea_TR) with those away from the sea (Int_PE, Int_TR and Int_Park) shows that the selection of blue colour is lower (in percentage) in the latter areas. Because colours are perceived by the sense of sight, the selection of a colour associated with the soundscape may be related also with visual aspects. Thus, in areas where the blue is predominant in the landscape a high percentage of people often selected this colour. The green selected for the areas limited to road traffic may be due to the presence of a small park in one of the two such areas. However, in the areas away from the sea, green colour was selected by a similar percentage of people, including those interviewed in the park. Surprisingly, yellow was the colour selected by the highest percentage of people in the green areas.

\subsubsection{Correspondence analysis between soundscape and colours}

The square root of the trace between soundscape quality and colours associated to the soundscape was 0.74 , indicating a strong association between these two variables $\left(\chi^{2}=\right.$ 142.31, $\mathrm{p}$-value $=4.967 \mathrm{e}^{-12}$ ).

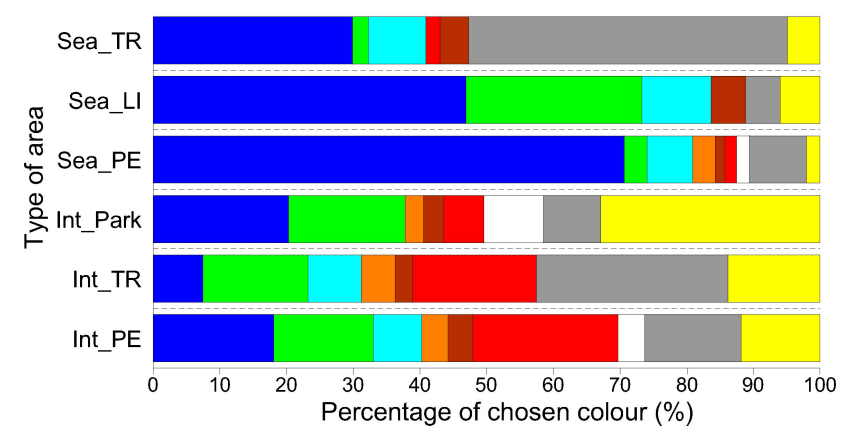

Figure 9: Percentage of people who had chosen a specific colour in the six types of area under study.

Likewise in the previous section, correspondence analyses was performed between the two variables (Figure 10). The first and second dimensions explain a high percentage of the variance $(82.1 \%)$. In particular, the first dimension explained $58.1 \%$ of the variance, and the second one $24.0 \%$. The contribution of each colour to the total inertia was considered only for the colours with a percentage in the first or second dimension higher than $11.1 \%$. Thus, blue, brown, grey, red and yellow were considered, as shown in Table 5.

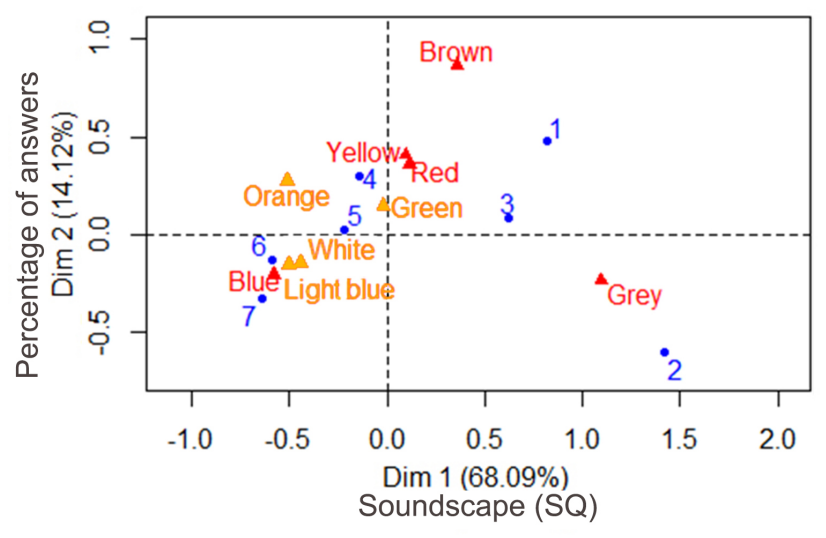

Figure 10: Correspondence analysis between soundscape (SQ) and colours associated to it. Blue dots represent the SQ ratings, red triangles the colours with a contribution higher than the $11.1 \%$, and orange triangles those with a contribution lower than the $11.1 \%$.

Dimension 1 is linked to positive soundscape ratings, that is neutral (4) or positive scores (5, 6 and 7), located on the left side of the $\mathrm{X}$ axis, while negative soundscape ratings are on the right side. The highest positive ratings (scores 6 and 7) are strongly associated with blue, the negative ones with grey (scores 1, 2 and 3). Dimension 2 is linked to the percentage of people who chose a specific colour. Blue and grey colours are the ones chosen most frequently by people (36.2\% and $20.5 \%$ respectively), whereas the per- 
Table 5: Dimension contribution and quality of the columns representation $\left(\cos ^{2}\right)$.

\begin{tabular}{ccccc}
\hline Colours & $\begin{array}{c}\text { Dim1: } \\
\text { SQ }\end{array}$ & $\cos ^{2}$ & $\begin{array}{c}\text { Dim2: } \\
\text { Percentage } \\
\text { of answers }\end{array}$ & $\cos ^{2}$ \\
\hline Blue & $\mathbf{2 4 . 8}$ & 0.91 & $\mathbf{1 1 . 1}$ & 0.08 \\
Brown & 1.1 & 0.09 & $\mathbf{3 0 . 9}$ & 0.53 \\
Green & 0.0 & 0.00 & 3.1 & 0.16 \\
Grey & $\mathbf{6 4 . 3}$ & 0.96 & $\mathbf{1 4 . 0}$ & 0.04 \\
Light blue & 6.1 & 0.59 & 3.7 & 0.07 \\
Orange & 1.9 & 0.39 & 2.6 & 0.11 \\
Red & 0.2 & 0.02 & 16.6 & 0.33 \\
White & 1.2 & 0.25 & 0.6 & 0.03 \\
Yellow & 0.4 & 0.07 & 17.4 & 0.64 \\
\hline
\end{tabular}

centage of people who chose other colours was lower than $11 \%$.

The worst represented colours were white, orange, light blue, as obtained in the previous analysis, and green. People who gave score 7 to the soundscape selected mainly blue colour (the contribution of blue is similar in both dimensions $24.8 \%$ and $11.1 \%$ ), and it is much better represented in dimension 1 than in dimension 2 ( $\cos ^{2} 0.91$ vs. 0.08). Score 6 is also related with the selection of blue and score 5 has low contribution on both dimensions. Score 4 is more related with red, yellow and weakly related to grey. Score 1 is similarly associated to brown, yellow, red and grey, while rating 2 is only associated to grey colour.

The quality of the presentation is quite high for most of the ratings, being scores 2 and 7 the best represented ones, with a value very close to 1 . Score 5 is the worst represented, with a quality of the representation of 0.43 in dimension 1 and 0.01 in dimension 2.

\subsection{Multiple correspondence analysis}

The results of multiple correspondence analysis performed considering together the three variables taken into account in the previous two correspondence analyses are shown in Figure 11. Dimension 1 is associated with location (near the sea or interior) and the type of traffic, while dimension 2 is linked to the number of people who selected a specific colour. Pedestrian areas nearby the sea are associated mainly with blue and light blue colours and to the highest soundscape scores. Grey colour is strongly associated with the lowest soundscape scores and areas open to traffic nearby the sea. The pedestrian areas away from the sea are close to soundscape score 4 , and to green and or- ange colours. Brown is the colour nearest to the areas open to traffic and away from the sea and presents a slight longer distance to yellow, red and green. The soundscape score 3 is strongly associated with the areas open to traffic and away from the sea, while red, yellow, green, white and orange are the nearest colours to the park, and soundscape score 4 is the nearest.

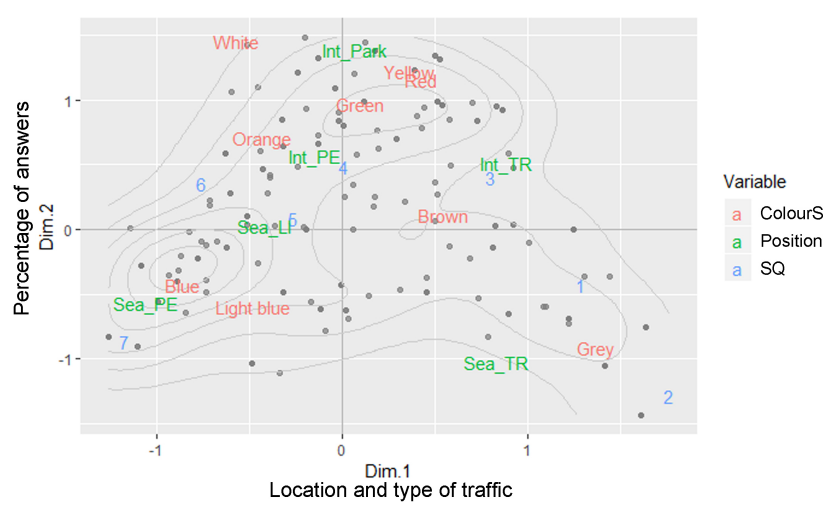

Figure 11: Output of the multiple correspondence analysis.

\section{Discussion}

Because many researchers agree that the performance of cognitive tasks improves when there is congruence between sound and colour [22, 45, 47], it should be advisable for noise and soundscape maps to use colours matching the features of sounds that they intend to represent in order to make the maps more intuitively interpretable.

In the present study, in the areas by the sea, the blue colour was predominantly chosen only when the soundscape was rated positive (scores 5-7), while when it was rated negative, in the areas with road traffic, although many people chose blue colour, the predominant one was grey, probably because it is associated to technology and pollution and their potential negative effects on health. In the areas by the seam it is likely that the landscape colour has a strong influence on the colour selection, but this pattern was not observed in all areas. For instance, in green areas the colour associated to the soundscape by the highest percentage of people was not green, as expected, but yellow. In other interior areas, where ochre and yellowish tones were predominant in the landscape, colours with none or minimal presence in the landscape (blue, red, green) were associated with the soundscape.

The results of this research show that people normally select colours according to the main source that they heard 
or thought to be heard despite its low sound level. For instance, during the interviews the sound from the sea was hardly to be heard from any of the locations; nevertheless many people chose water as the predominant sound source. Participants agree in the association of water sounds with blue and traffic noise with grey. However, when voices have a strong presence in the areas, the outcomes show that participants select a wider range of colours.

Correspondence analyses show that blue, grey, red and yellow are colours represented with a satisfactory quality in the model between soundscape and colours, and in the one between soundscape and location. Green was well represented in the correspondence analysis between location and colours, so it is associated with the location. Brown colour was well represented in the analysis between colour and soundscape, so it is only associated with the soundscape rating.

Results show that there is association between colour selected and location, as well as colour and soundscape. That means that the colour associated by people to a soundscape is not only linked to the acoustic environment features, but to the way that people experience the acoustic environment in a specific place, according to the definition of soundscape given in the ISO 12913-1.

These outcomes reveal that the use of colours as additional descriptors of the soundscape provides supplementary visual and intuitive information about it and may be useful especially for the representation of its spatial variability. The use of such colours in maps would be much more intuitive for non-specialists in acoustics than numeric indicators. In the last decade, community based measurement techniques of environmental noise are growing due to the development and extensive use of mobile technology $[14,24,41,60]$. The screen size of mobile phones is a limitation for the use of legends or explanatory notes linked to environmental sounds applications. Thus, the deployment of colours congruent with environmental sounds may make these applications more intuitive and user friendly.

\section{Conclusions}

The potential of using colours as additional parameter to describe the soundscape has been investigated. The results show that colours add supplementary and more intuitive information on soundscape to those provided by the acoustic parameters.
Linear regressions models were used to compare the capability of prediction of the soundscape quality of objective acoustic parameters and colours. The comparison of the performance of both models show that colours can be as good descriptors of the soundscape quality as acoustic parameters.

Correspondence analyses were performed to evaluate the relationship of each colour chosen by the interviewees with the type of areas and the soundscape. In the studied context, the outcomes show that soundscape of areas nearby the sea are always associated with the blue colour, often associated to positive emotions such as calmness, relaxation or happiness [26], whereas the soundscape in areas away from the sea is more related with green, yellow or red colours independently of the type of road traffic. The exclusion of the former colours from the linear regression model predicted by colours may be due to the absence of the variable position in the analysis. Thus, these colours do not significantly explain the variance of the soundscape rating in the whole study area, although they have a satisfactory association with the soundscape quality in the interior areas.

The areas nearby the sea and open to traffic areas were also associated with the blue colour, probably because of the influence of the visual elements on the sound perception, but also with the grey colour, associated to negative emotions such as sadness, depression or confusion [23, 26]. In the areas away from the sea and open to traffic a wider range of chosen colours was observed and the percentage of participants who selected grey colour was much lower than in the areas nearby the sea and open to traffic. The difference on the colour selection between areas nearby the sea and those far away, both with predominant road traffic noise, can be also appreciated in the ratings on the soundscape. Areas nearby the sea and open to traffic are associated to the lowest scores (1 and 2), while those away from the sea and open to traffic are more linked to a lowmedium score (3). This may be due to the influence of the coherence and expectations $[8,9,55]$ on the soundscape. People tend to give lower scores where the soundscape is not coherent with the landscape or it does not match their expectation.

The outcomes are interesting, especially considering the potential of using colours as additional parameter to represent the spatial variability of the soundscape in urban areas and to provide immediate and meaningful information for non-specialists. However, more research is needed to evaluate the association of each colour with specific emotions associated to the acoustic environment. 
Acknowledgement: The research was funded by the People Programme (Marie Curie Actions) of the European Union's 7th Framework Programme FP7/2007-2013 under REA grant agreement $n^{\circ} 290110$, SONORUS “Urban Sound Planner”.

\section{References}

[1] Aizawa, K., Kamogawa, T., Arimitsu, A., \& Toi, T. (2014). Development of a new loudness model in consideration of audio-visual interaction. In Internoise 2014 (pp. 1-10). Melbourn (Australia).

[2] Aletta, F., Kang, J., \& Axelsson, O. (2016). Soundscape descriptors and a conceptual framework for developing predictive soundscape models. Landscape and Urban Planning, 149, 65-74. https: //doi.org/10.1016/j.landurbplan.2016.02.001

[3] Axelsson, Ö., Nilsson, M. E., \& Berglund, B. (2010). A principal components model of soundscape perception. The Journal of the Acoustical Society of America, 128(5), 2836-2846. https://doi. org/10.1121/1.3493436

[4] Barbiere, J. M., Vidal, A., \& Zellner, D. A. (2007). The Color of Music: Correspondence through Emotion. Empirical Studies of the Arts, 25(2), 193-208. https://doi.org/10.2190/A704-56475245-R47P

[5] Bendixen, M. (1995). Compositional perceptual mapping using chi-squared tree analysis and Correspondence Analysis. Journal of Marketing Management, 11, 571-581.

[6] Bendixen, M. (2003). A Practical Guide to the Use of Correspondence Analysis in Marketing Research. Marketing Bulletin, 14, 1-15.

[7] Berman, M. G., Jonides, J., \& Kaplan, S. (2008). The Cognitive Benefits of Interacting With Nature. Psychological Science, 19(12), 1207-1212.

[8] Brambilla, G., Gallo, V., Asdrubali, F., \& D’Alessandro, F. (2013). The perceived quality of soundscape in three urban parks in Rome. The Journal of the Acoustical Society of America, 134(1), 832-9. https://doi.org/10.1121/1.4807811

[9] Bruce, N. S. (2011). The effects of expectation on the perception of soundscapes. Applied Acoustics, 85, 1-11. https://doi.org/10. 1016/j.apacoust.2014.03.016

[10] Cain, R., Jennings, P., \& Poxon, J. (2013). The development and application of the emotional dimensions of a soundscape. Applied Acoustics, 74(2), 232-239. https://doi.org/10.1016/j.apacoust. 2011.11.006

[11] Caivano, J. (1994). Color and Sound: Physical and Psychophysical Relations. Color Research \& Application, 19(2), 126-133. https: //doi.org/10.1111/j.1520-6378.1994.tb00072.x

[12] Chen, Y., Lou, Z., Ji, L., Liu, Y., Han, F., Wang, H., .. Li, X. (2018). An extended research of crossmodal correspondence between color and sound in psychology and cognitive ergonomics. Peer), 6, e4443. https://doi.org/10.7717/peerj.4443

[13] Cirafici, A., Natalia, A., \& Senese, V. P. (2012). Acoustic comfort aboard transportation systems. Multisensory evaluation by means of virtual reality and subjective testing. Interaction of colour scheme and noise in the metro interior. Color and Colorimetry. Multidisciplinary Contributions, VIII, 119-127.

[14] Cordeiro, J., \& Makelberge, N. (2010). HURLY-BURLY: An experimental framework for sound based social networking. In The 16th International Conference on Auditory Display (pp. 109-113).

[15] Cox, T. J. (2008). The effect of visual stimuli on the horribleness of awful sounds. Applied Acoustics, 69(8), 691-703. https://doi. org/10.1016/j.apacoust.2007.02.010

[16] Fastl, H. (2004). Audio-visual interactions in loudness evaluation. Proceedings of the 18th ICA. Retrieved from http://www.mmk.ei. tum.de/publ/pdf/04/04fas1.pdf

[17] Fastl, H., \& Zwicker, E. (2007). Psycho-acoustics: Facts and models. (T. S. Huang, T. Kohonen, \& M. R. Schroeder, Eds.), SpringerVerlag Berlin Heidelberg (Third Edit). Springer Series in Informatin Science.

[18] Giannakis, K., \& Smith, M. (2001). Imaging Soundscapes: Identifying Cognitive Associations between Auditory and Visual Dimensions. Musical Imagery, 51-69.

[19] Greenacre, M. (1984). Theory and Applications of Correspondence Analysis. (A. Press, Ed.). London.

[20] Greenacre, M. (2008). La práctica del análisis de correspondencias. Retrieved from http://www.fbbva.es/TLFU/dat/DE_ 2008_practica_analisis_correspondencias.pdf\%5Cnhttp: //www.fbbva.es/TLFU/tlfu/esp/publicaciones/libros/ fichalibro/index.jsp?codigo $=300$

[21] Hamilton-Fletcher, G., Ward, J., \& Wright, T. D. (2015). CrossModal Correspondences Enhance Performance on a Colour-toSound Sensory Substitution Device. Multisensory Research, (December), 1-27. https://doi.org/10.1163/22134808-00002519

[22] Hocking, J., \& Price, C. J. (2008). The influence of colour and sound on neuronal activation during visual object naming. Brain Research, 1241, 92-102. https://doi.org/10.1016/j. brainres.2008.08.037

[23] Jalil, N. A., Yunus, R. M., \& Said, N. S. (2013). Students' Colour Perception and Preference: An Empirical Analysis of its Relationship. Procedia - Social and Behavioral Sciences, 90(InCULT 2012), 575-582. https://doi.org/10.1016/j.sbspro.2013.07.128

[24] Kanjo, E. (2010). NoiseSPY: A real-time mobile phone platform for urban noise monitoring and mapping. Mobile Networks and Applications. https://doi.org/10.1007/s11036-009-0217-y

[25] Kassambara, A. (2017). Practical Guide to Principal Component Methods in R. In Multivariate Analysis II. STHDA.

[26] Kaya, N., \& Epps, H. (2004). Relationship between color and emotion: a study of college students. College Student Journal, 38(3), 396-405. Retrieved from https://nzdis.org/projects/ attachments/299/colorassociation-students.pdf

[27] Kim, K. H., Gejima, A., Iwamiya, S. I., \& Takada, M. (2011). The effect of chroma of color on perceived loudness caused by noise. In 40th International Congress and Exposition on Noise Control Engineering 2011, INTER-NOISE 2011.

[28] Kontukoski, M., Paakki, M., Thureson, J., Uimonen, H., \& Hopia, A. (2016). Imagined salad and steak restaurants: Consumers' colour, music and emotion associations with different dishes. International Journal of Gastronomy and Food Science, 4, 1-11. https://doi.org/10.1016/j.ijgfs.2016.04.001

[29] Koufakou, A., Ortiz, E. G., Georgiopoulos, M., Anagnostopoulos, G. C., \& Reynolds, K. M. (2008). A scalable and efficient outlier detection strategy for categorical data. Proceedings - International Conference on Tools with Artificial Intelligence, ICTAI, 2, 210-217. https://doi.org/10.1109/ICTAI.2007.125

[30] Lê, S., Josse, J., \& Husson, F. (2008). FactoMineR: A Package for Multivariate Analysis. Journal of Statistical Software, 25(1), 1-18. https://doi.org/10.18637/jss.v025.i01 
[31] Lee, Y.-J., \& Lee, J. (2006). The development of an emotion model based on colour combinations. International Journal of Consumer Studies, 30(2), 122-136. https://doi.org/10.1111/j.14706431.2005.00457.x

[32] Lewkowicz, D. J., \& Ghazanfar, A. A. (2009). The emergence of multisensory systems through perceptual narrowing. Trends Cogn. Sci. (Regul. Ed.), 13 (11), 470-478.

[33] Lichtenfeld, S., Elliot, A. J., Maier, M. A., \& Pekrun, R. (2012). Fertile Green: Green Facilitates Creative Performance. https:// doi.org/10.1177/0146167212436611

[34] Lindborg, P. (2012). Correlations Between Acoustic Features, Personality Traits and Perception of Soundscapes. In Proceedings ofthe International Conference on Music Perception and Cognition. Thessaloniki (Greece).

[35] Lindborg, P., \& Friberg, A. K. (2015). Colour Association with Music Is Mediated by Emotion: Evidence from an Experiment Using a CIE Lab Interface and Interviews. PLOS ONE, 10(12), 1-26. https://doi.org/10.1371/journal.pone.0144013

[36] Ma, H., \& Nie, W. (2014). Influence of visual factors on noise annoyance evaluation caused by road traffic noise in indoor environment. In Internoise 2014 (pp. 1-8). Melbourne (Australia).

[37] Maffei, Luigi; Iachini, Tina; Masullo, Massimiliano; Aletta, Francesco; Sorrentino, F. S. V. P. . R. F. (2013). The Effects of Vision-Related Aspects on Noise Perception of Wind Turbines in Quiet Areas. International Journal of Environmental Research and Public Health, 10(5), 1681-1697. https://doi.org/10.3390/ ijerph10051681

[38] Maffei, L., lachini, T., Masullo, M., Aletta, F., Sorrentino, F., Senese, V. P., \& Francesco, R. (2013). The Effects of Vision-Related Aspects on Noise Perception of Wind Turbines in Quiet Areas. International Journal of Environmental Research and Public Health, 10(5), 1681-1697. https://doi.org/10.3390/ijerph10051681

[39] Maffei, L., Masullo, M., Aletta, F., \& Di Gabriele, M. (2013). The influence of visual characteristics of barriers on railway noise perception. Science of the Total Environment, 445-446, 41-47. https://doi.org/10.1016/j.scitotenv.2012.12.025

[40] Maffei, L., Puyana-Romero, V., Brambilla, G., di Gabriele, M., \& Gallo, V. (2014). Characterization of the soundscape of urban waterfronts. In Forum acusticum. Kraków (Poland).

[41] Maisonneuve, N., Stevens, M., Niessen, M. E., \& Steels, L. (2009). NoiseTube: Measuring and mapping noise pollution with mobile phones. Environmental Science and Engineering (Subseries: Environmental Science), 215-228. https://doi.org/10.1007/978-3540-88351-7-16

[42] Maisonneuve, N., Stevens, M., \& Ochab, B. (2010). Participatory noise pollution monitoring using mobile phones. Information Polity, 15(1-2), 51-71. https://doi.org/10.3233/IP-2010-0200

[43] Marks, L. E. (1975). On colored-hearing synesthesia: cross-modal translations of sensory dimensions. Psychological Bulletin, 82(3), 303-331. https://doi.org/10.1037/0033-2909.82.3.303

[44] Marks, L. E. (1987). On Cross-Modal Similarity: Auditory-Visual Interactions in Speeded Discrimination. Journal of Experimental Psychology: Human Perception and Performance, 13(3), 384-394. https://doi.org/10.1037/0096-1523.13.3.384

[45] Marks, L. E., Ben-artzi, E., \& Lakatos, S. (2003). Cross-modal interactions in auditory and visual discrimination. PeerJ, 6. https: //doi.org/10.1016/S0167-8760

[46] McHugh, M. L. (2013). The Chi-square test of independence. Biochemia Medica, 23(2), 143-149. https://doi.org/10.11613/BM. 2013.018
[47] Melara, R. D. (1989). Dimensional interaction between color and pitch. Journal of Experimental Psychology: Human Perception and Performance. US: American Psychological Association. https: //doi.org/10.1037/0096-1523.15.1.69

[48] Menzel, D., Haufe, N., \& Fastl, H. (2010). Colour-influences on loudness judgements. Proc. 20th ICA Sydney, (August), 2-6. Retrieved from http://www.mmk.ei.tum.de/publ/pdf/10/10men2. pdf

[49] Moos, A., Simmons, D., Simner, J., \& Smith, R. (2013). Color and texture associations in voice-induced synesthesia. Frontiers in Psychology, 4(SEP). https://doi.org/10.3389/fpsyg.2013.00568

[50] Organization for Standardization. ISO 12913-1. Acoustics Soundscape (2014).

[51] Palmer, S. E., Schloss, K. B., Xu, Z., \& Prado-León, L. R. (2013). Music-color associations are mediated by emotion. Proceedings of the National Academy of Sciences of the United States of America, 110(22), 8836-41. https://doi.org/10.1073/pnas.1212562110

[52] Patsouras, C., Filippou, T., \& Fastl, H. (2002). Influences of color on the loudness judgement. Proc. Forum Acusticum, 1-6. Retrieved from http://www.mmk.ei.tum.de/publ/pdf/02/02pat5. pdf

[53] Pravossoudovitch, K., Cury, F., Young, S. G., \& Elliot, A. J. (2014). Is red the colour of danger? Testing an implicit red-danger association. Ergonomics, 57(4), 503-510. https://doi.org/10.1080/ 00140139.2014.889220

[54] Pridmore, R. W. (1992). Music and color: Relations in the psychophysical perspective. Color Research \& Application, 17(1), 57-61. https://doi.org/10.1002/col.5080170110

[55] Puyana Romero, V., Brambilla, G., di Gabriele, M., Gallo, V., \& Maffei, L. (2015). The influence of the soundscape on the tourists' environmental quality perception. In Euronoise. Maastricht (Holland).

[56] Puyana Romero, V., Ciaburro, G., \& Maffei, L. (2015). The influence of colours on the sound environment perception. In XIII International Forum Le Vie dei Mercanti. Heritage and technology. Mind knowledge experience (Vol. 1). Aversa-Capri (Italy).

[57] Rader, T., Morigana, M., Matsui, T., Fastl, H., Kuwano, S., \& Namba, S. (2004). Crosscultural effects in audio-visual interactions. In Transactions of the Technical Committee of Noise and Vibration of the Acoustical Society of Japan (2004), N-2004-, 1-6.

[58] Rana, R. (2010). Ear-Phone: A context-aware End-to-End Participatory Urban Noise Mapping System.

[59] Rostami, M., Izadan, H., \& Mahyar, F. (2013). Colour Emotion Models, CIELAB Colour Coordinates, and Iranian Emotional Responses. In Proceeding of the 12th Congress of the International Colour Association (pp. 839-842).

[60] Schweizer, I., Bärtl, R., Schulz, A., Probst, F., \& Mühlhäuser, M. (2011). NoiseMap - Real-time participatory noise maps. World, to appear.

[61] Sebba, R. (1991). Structural correspondence between music and color. Color Research \& Application, 16(2), 81-88. https://doi. org/10.1002/col.5080160206

[62] Song, J., Ma, H., Yang, Q., \& Zhang, S. (2011). Interaction of color perception and annoyance evaluation of road traffic noise. In Internoise 2011 (pp. 2120-2125). Osaka (Japan).

[63] Strle, G., Pesek, M., \& Marolt, M. (2016). Towards User-Aware Music Information Retrieval: Emotional and Color Perception of Music. In M. Tkalčič, B. De Carolis, M. de Gemmis, A. Odić, \& A. Košir (Eds.), Emotions and Personality in Personalized Services: Models, Evaluation and Applications (pp. 327-353). Cham: 
Springer International Publishing. https://doi.org/10.1007/9783-319-31413-6_16

[64] Tsang, T., \& Schloss, K. B. (2010). Associations between Color and Music are Mediated by Emotion and Influenced by Tempo. The Yale Review of Undergraduate Research in Psychology, 82-93. Retrieved from http://www.yale.edu/yrurp/issues/ TsangandSchloss, TheColorofMusic.pdf\%5Cnpapers2:// publication/uuid/CCA549D1-EC20-497F-B9F7-CB440CF5E29C
[65] Um, J., Eum, K., \& Lee, J. (2002). A study of the emotional evaluation models of color patterns based on the adaptive fuzzy system and the neural network. Color Research \& Application, 27(3), 208-216. https://doi.org/10.1002/col.10052

[66] Ward, J., Huckstep, B., \& Tsakanikos, E. (2006). Sound-colour synaesthesia: To what extent does it use cross-modal mechanisms common to us all? Cortex, 42, 264-280. 